\title{
A Suggested Tests Battery to Determine the Abilities of Savant Syndrome of Autism
}

\author{
Marwa Mohamed El-Sayed Abdel Bari \\ MA in Autism-Psychological Health Dept., Helwan University- Egypt
}

\begin{abstract}
The current research aimed to identify the significance of A suggested Tests Battery in determining the abilities that include language, mathematics, art, music, calculus, visual, spatial, mechanics and memory for those with the Savant syndrome. The differences between those who are Savant with autism syndrome and those who are accustomed to these tests were ascertained to ensure that these tests are suitable for those with syndrome and the contribution of the memory test in the prediction of each of the seven tests. The study relied on a sample consisted of 35 students with autism and 35 normal students, they all utilized the tests battery. And the results showed that the suggested tests battery was effective in in determining the abilities that include language, mathematics, art, music, calculus, visual, spatial, mechanics and memory for those with the Savant syndrome.
\end{abstract}

Keywords: Savant Syndrome - Savantism - Autism

DOI: $10.7176 /$ RHSS/9-10-02

Publication date:May $31^{\text {st }} 2019$

\section{INTRODUCTION:}

Savant comes from Latin sapere ("to be SMART ") where "savant" meaning "to know". Savant" shares roots with the English words "sapient" ("hold plentifully wisdom") and "sage" ("having or showing wisdom through joined-up thinking and experience"). While the Britannica encyclopedia referred to Savant syndrome, as an unusual condition wherein a person of less than normal intelligence or severely limited emotional range has prodigious intellectual gifts in a particular area. Mathematical, musical, artistic, and mechanical abilities have been among the talents expressed by savants. Examples include performing rapid mental calculations of huge sums, playing lengthy musical compositions from memory after a single hearing, and repairing complicated mechanisms without training. About 10 percent of autistic people, exhibit savant syndrome and are recognized as autistic savants. Non-autistic intellectually disabled people may also be savants, though the incidence among them is much lower. Individuals with savant skills were first aforesaid by Down in 1887 . He used the term idiot savant to refer to persons who were intellectually impaired with rare abilities. At this time, the term idiot was the generally agreed classification system for individuals with an IQ less than 25 (Hallahan, Kauffman, \& Pullen, 2009). Spitz (1995) offers an alternative view The most common types of savant skill are exhibited in the visual arts, particularly drawing (Selfe,1983), musical performance (Miller, 1989), and certain arithmetic skills, including calendar calculating (the ability to give the correct day of the week for a given date) and prime number derivation (Sacks, 1985). and "savant syndrome" (Treffert,1988) have been suggested as alternatives to traditional terminology. Today, these individuals may be referred to as mono-savants if they have a skill in one specific area. This is the most common type of savant (Straus, 2014). The term savant syndrome is commonly used, although technically this term refers to individuals with multiple unique skills (Heaton \& Wallace, 2004). Savant skills are always characterized by exceptional memory, specifically within particular domains (Heaton \& Wallace, 2004; Straus,2014). Calculating skills are noticed in calendar calculating or the ability to calculate large numbers or prime numbers-and may occur even when individuals are unable to complete simple arithmetic tasks. Mechanical or spatial skills include the ability to measure distances accurately without instruments and the ability to precisely construct complicated models or maps, as well as other direction-finding skills (Wallace, 2008). Other savant skills are also reported such as polyglot (extraordinary language skills), synesthesia (experiencing crossed stimuli-such a "hearing" colors), and exceptional knowledge of a specific topic (Darold \& Treffert,2010). There was no evidence that those individuals with either exceptional cognitive or parent-rated skills had higher rates of repetitive or stereotyped behaviors /interests than those who did not. Thus, although all participants showed abnormalities in this domain, the severity of such behaviors was not related to savant abilities.(Patricia Howlin,2009).that savants have privileged access to lower level, less-processed information, before it is packaged into holistic concepts and labels - savants tap into or read off information that exists in all of our brains; but this information is normally beyond conscious awareness owing to top-down inhibition (Snyder \& Mitchell 1999; Snyder et al 2004).

O'Connor \& Hermelin $(1988,1991)$ suggested that a tendency to repetitive behavior and/or preoccupations with a restricted area of interest were crucial features of individuals with savant syndrome. They also referred that 'autistic savants' showed a particular interest in one specific topic (names, buttons, birthdates, etc.) and in the repetitive ordering of possessions. 


\section{THE STUDY CONCEPTS:}

2.1 Definition of Savant syndrome: It is a rare condition suffering from a neuro-developmental disorders characterized by amazing talent and be innate or acquired in exceptional skills such as music, art, calendar calculation, spatial, mechanical and visual fields and the huge memory, rapid calculation and language. or it may be in one skill or more and the degree of intelligence between 40 to 70 degrees but may be above 70 in $25 \%$ of cases (according to Darold Trafford) and characterized by deficiencies in three areas of social interaction and communications (verbal -non-verbal), stereotypical behaviors and limited activities and interests. This is not limited to Autism disorder but also to a number of other disabilities such as visual impairment, hearing impairment, brain injury and mental retardation as we find many people with savant syndrome who have been diagnosed with autism are influential models in their societies,

\section{OBJECTIVES OF THE STUDY:}

The current research aimed to identify the significance of the battery tests in determining the abilities that include language, mathematics, art, music, calculus, visual, spatial, mechanics and memory for those with the Savant syndrome. The differences between those who are Savant with autism syndrome and those who are accustomed to these tests were ascertained to ensure that these tests are suitable for those with syndrome and the contribution of the memory test in the prediction of each of the seven tests

\section{RESEARCH HYPOTHESES:}

4.1 The first hypothesis states that "there are differences with statistically significance between the students in the language test (as a total degree and as sub-dimensions) attributable to the benefit of those with the autistic Savant syndrome".

4.2 The second hypothesis states that "there are differences with statistically significance between students in mechanics (as a total degree and as sub-dimensions) attributable to the benefit of those who have autistic Savant syndrome".

4.3 The third hypothesis states that "there are differences with statistically significance between students in spatial visual capacity (as a total degree and as sub-dimensions) attributable to the benefit of those with the autistic Savant syndrome".

4.4 The fourth hypothesis states that "there are differences with statistically significance between students in music (as a total degree and as sub-dimensions) attributable to the benefit of those with the autistic Savant syndrome ".

4.5 The fifth hypothesis states that "there are differences with statistically significance between students in art (as a total degree and as sub-dimensions) attributable to the benefit of those with the autistic Savant syndrome".

4.6 The sixth hypothesis states that "there are differences with statistically significance between the students in the mathematics test (as a total degree and as sub-dimensions) attributable to the benefit of those with the autistic Savant syndrome".

4.7 The seventh hypothesis states that "there are differences with statistically significance between students in the assessment (as a total degree and as sub-dimensions) attributable to the benefit of those with the autistic Savant syndrome".

\section{METHODOLOGY}

\subsection{Sample:}

The total sample comprised of 70 individuals (35 normal- 35 first diagnosed with autism)

\subsection{Study Procedures:}

The study was conducted according to the following steps:

5.2.1 Identification of the problem and its dimensions.

5.2.2 Reading the previous studies and researches that which deal with the variables of this study

5.2.3 Preparation of the tools of the study and examination of its validity and stability.

5.2.4 Selection of the sample of the study

5.2.5 Homogeneity among the sample members by applying the appropriate tools.

5.2.6 Application of the study tools to the members of groups, and grading scores on the scale.

\section{RESULTS and DISCUSSIONS: -}

The current research aimed to identify the significance of the battery tests in determining the abilities that include language, mathematics, art, music, calculus, visual, spatial, mechanics and memory for those with the Savant syndrome. The differences between those who are Savant with autism syndrome and those who are accustomed to these tests were ascertained to ensure that these tests are suitable for those with syndrome and the 
contribution of the memory test in the prediction of each of the seven tests. We also discuss the results of the current research and then attempt to interpret and discuss these results in light of the theoretical framework and the results of previous studies.

To verify the validity of the First hypothesis, the researcher relied on the test of two independent samples to detect the significance of differences between the two groups (autism and normal). Table (1) shows the average and standard deviations of the Arabic language scores in both groups. Figure (1) refers to the averages of normal and Autistic in the language test as a total score and as sub-dimensions. In terms of the table (1) it is clear that there are significant differences at the level of significance 0.05 between the average degrees of autism and normal in reading in favor of autistic, Hence, the researcher presents the result of the first hypothesis and its interpretation, where differences were found in the level of significance in both reading and spelling and linguistic correction for the benefit of autism with the syndrome of talented, as explained by Trevirt, 2010 that the Savant syndrome, some of them are characterized by the talent of language able to read well And they read through the different directions from the right to the north and vice versa and from the bottom to the top and vice versa, as well as there are cases that can spell words conversely once the word once heard, but for the skill of correction language they have the ability to speak fluently in the language with no errors as if They may be able to read a number of books in different fields and answer questions, which can be traced back to their estrangement memories in reading the information that was read. This is also the opposite of the normal as they gave a response in understanding the story.

To verify the validity of the second hypothesis, the researcher relied on the test of two independent samples to detect the significance of differences between the two groups (autistic and normal). The table shows the average and standard deviations of the degrees of mechanics in both groups. Figure (2) refers to the normal and autistic averages in mechanics as a total score and as sub-dimensions. Hence, the researcher presents the result of the second hypothesis and its interpretation. It was found that those with Savant syndrome have the ability to disassemble and install a motor vehicle or refrigerator, although they have not studied mechanics, but they can. This is what Trevert 2010 explained. The mechanics of motion, torque, stability, relative motion, Throwing, disassemble and structure. The most skillful skill is the relative motion through the use of the roulette and the location of the fall of the ball, which is designed to achieve the desired objective, also the movement of projectiles and disassemble The composition of a motor is one of the most difficult skills to achieve in the test of mechanical ability, unlike normal could not achieve a response in these three skills.

To verify the validity of the third hypothesis, the researcher relied on the test of two independent samples to detect the significance of differences between the two groups (autistic and normal). Figure (3) refers to the average of the normal and the autistic in spatial visual capacity as a total degree and as sub-dimensions. Thus, the researcher presented the result of the third hypothesis and its interpretation, where the result was found in favor of autism with the syndrome of Savant, where the three skills of counting were measured through geometric shapes that were designed to suit the questions addressed to them, they had the ability to respond quickly to their questions and give the answer. Some of them are given an answer after a long period of time, also in the measurement of lengths, spaces, sizes and measuring distances, which used tools with 3D graphics and were like puzzles. Through these questions they explained that they have the ability to solve puzzles but may be given a quick response or may be delayed for some time. Unlike Normal.

In order to verify the fourth hypothesis, the researcher relied on two independent samples to detect the differences between the two groups (autism and normal). Figure (4) indicates averages of Normal and autistic in music as a whole degree and as sub-dimensions. Hence, the researcher presents the result of the fourth hypothesis and its interpretation, where the researcher found that the Savant syndrome of autism even though they have the ability to achieve the most difficult skills are the distinction of absolute pitch and the ability to play classical music once they hear, their skills in music similar to the skill of Professional musicians. They have the ability to transfer music through keys and recognize tones, but they have difficulty responding to music written in an unfamiliar way. They have the ability to respond to familiarly written music, which is evident in the ability to measure speed and slowness. Savant by autism, and as a result they conform to the tradition of music or the regular form of music, and in some questions, they improvise music.

To verify the fifth hypothesis, the researcher relied on a $\mathrm{T}$ test for two independent samples to detect the significance of differences between the two groups (autistic and normal). Figure (5) refers to normal and autistic averages in art as a total degree and as sub-dimensions.Hence, the researcher presented the result of the fifth hypothesis and its interpretation, where the level of significance in the drawing (0.05) was found for the benefit of the Savant syndrome of autism, where they demonstrated the ability to produce complex artistic outputs and correct with the ability to maintain the unity of the work of art and the correlation between the elements Design until the design appears as one whole, monolithic and interconnected in its parts. It cannot be deleted or added. The work is complete and nothing can be added to it. In a single case, this is what Selfe (1977) reported. The three-and-a-half-year-old Nadia showed remarkable ability in drawing, even though she suffers from autism, as well as the identification of the Savant syndrome of autism by maintaining proportion and proportionality to 
artistic work, Maintain equilibrium, harmony, repetition and rhythm associated with the sense of movement and diversity while taking into account the stability of size. Also noticeable in the sculpture of the Savant syndrome of autism is characterized by high accuracy and harmony in the work and the ability to enrich the work of art by adding gradations or color peeling or color sense to create harmony, through evolution One of them has the ability to retain the absolute size of a picture in an animal drawing. Through the image he can realize the threedimensional shape and he will sculpt it. The work will be presented in the appendixes, since their abilities are not limited to painting but sculpture also with the ability to preserve the following values are harmony, frequency, proportion, proportionality, technical work unit, equilibrium and rhythm.

In order to verify the sixth hypothesis, the researcher relied on two independent samples to detect the significance of differences between the two groups (People with savant autism syndrome and normal). Figure (6) refers to the averages of normal and autistic individuals with the Savant syndrome in mathematics as a total score and as sub-dimensions. From here, the researcher presents the result of the sixth hypothesis and its interpretation. The researcher found that those with the Savant syndrome of autism have a rapid ability to calculate the initial processes including addition, subtraction, multiplication and division. This is also evident (Tammet, D., 2006) It takes from five to seven seconds for any number of up to six numbers. They also have a high capacity for numerical coding. They have a fast ability to remember numbers and their corresponding letters to convert letters of any word into numbers. They can also generate future expectations. And they also have the ability to sequence The logical steps are not repetitive and sequential to solve the problem, as they have created a rapid capacity to fill a patch of 64 square, compared to the normal took a longer time to solve the calculations and they found difficulties for promising up to six, and they were difficult to ability On numerical reasoning in generating future expectations and numerical coding and could not pass the logical sequence to solve the problem.

To verify The seventh hypothesis, the researcher relied on a $\mathrm{T}$ test for two independent samples to detect the significance of differences between the two groups (autistic and normal).Figure (7) indicates averages of normal and autistic individuals in the calendar as a whole degree and as sub-dimensions.Hence, the researcher presents the result of the seventh hypothesis and its interpretation. The Savant syndrome is characterized by the ability to determine any day for any date in the time period in the past 50 years or the present or the future to fifty years, as well as the ability to determine the corresponding day of the Hijri date, It takes five seconds to determine the Gregorian and Hijri day, different from the natural ones. Through the above, we find statistically significant differences for the benefit of the Savant syndrome in all tests (mathematics, calculus, language, spatial, mechanics, music, art). The skills that included each test were identified to determine the skills of the Savant syndrome of autism in each test. A special memory test was conducted for the Savant syndrome and was applied to a sample of Savant individuals with autism syndrome to predict their ability to apply their own test and determine the skills that characterize each test.

\section{REFERENCES}

1. Darold, A., \& Treffert, D. (2010). Islands of genius: The bountiful mind of the autistic,acquired, and sudden savant. Philadelphia, PA: Jessica Kingsley Publishers.

2. Hallahan, D. P., Kauffman, J. M., \& Pullen, P. C. (2009). Exceptional learners: Introduction to special education (11th ed.). Upper Saddle River, NJ: Pearson.

3. Heaton, P. K., \& Wallace, G. L. (2004). Annotation: The savant syndrome. Journal of Child Psychology and Psychiatry, 45, 899-911.

4. O'Connor, N. \& Hermelin, B. (1988). Annotation: low intelligence and special abilities. J. Child Psychol. Psychiatry 29, 391-396. (doi: 10. 111 1/j. 1469-7610.1988. tb00732.x)

5. O'Connor, N. \& Hermelin, B. (1991). Talents and preoccupations in idiots-savants. Psychol. Med. 21, 959

6. Patricia Howlin, Susan Goode, Jane Hutton and Michael Rutter(2009).Savant Skills in Autism: Psychometric Approaches and Parental Reports,Philosophical Transactions: Biological Sciences, Vol. 364, No. 1522, Autism and Talent (May 27, 2009), pp. 1359-1367. URL: https://www.jstor.org/stable/40485907

7. Selfe, L. (1977). Nadia: a case of exceptional drawing ability in an autistic child .London: Academic Press.

8. Selfe, L. (1983). Normal and Anomalous Representational Drawing Ability in Children, Methuen, London.

9. Snyder, A. W., Bossomaier, T. \& Mitchell, D. J. 2004 Concept formation: Object' attributes dynamically inhibited from conscious awareness. J. Integr. Neurosci. 3, 31-46. (doi: 10. 1142/S0219635204000361)

10. Snyder, A. W. \& Mitchell, D. J. 1999 is integer arithmetic fundamental to mental processing? The mind's secret arithmetic. Proc. R. Soc. Lond. B 266, 587-592. (doi: 10. 1098/rspb. 1999.0676)

11. Spitz, H. (1995). Calendar calculating idiots' savants and the smart unconscious. New Ideas Psychol. 13: 167-192.

12. Straus, J. (2014). Idiot savants, retarded savants, talented aments, mono-savants, autistic savants, just plain savants, people with savant syndrome, and autistic people who are good at things: A view from disability studies. Disability Studies Quarterly, 34. Retrieved from http://dsq-sds.org/article/view/3407/3640. 
13. The Editors of Encyclopaedia Britannica (2018).Savant syndrome Nov 21, 2018 .url:https://www.britannica.com/science/savant-syndrome

14. Treffert, D. (1988). The idiot savant: a review of the syndrome. Am. J. Psychiatry 145: 563-572.

15. Wallace, G. (2008). Neuropsychological studies of savant skills: Can they inform the neuroscience of savantness? Roeper Review, 30, 229-246.

Table (1): T Test results to detect differences in the arithmetic averages of the language test scores of autistic and

\begin{tabular}{|l|l|l|l|l|}
\hline Variable & Group & N & Arithmetic Averages & Standard Deviations \\
\hline \multirow{3}{*}{ reading } & Autism SAVANT & 35 & 38.74 & 19.136 \\
\cline { 2 - 5 } & Normal & 35 & 29.26 & 9.485 \\
\hline \multirow{3}{*}{ linguistic correction } & $\begin{array}{l}\text { Autism } \\
\text { SAVANT }\end{array}$ & 35 & 1.49 & 1.961 \\
\cline { 2 - 5 } & Normal & 35 & 0.09 & 0.284 \\
\hline \multirow{5}{*}{ story comprehension } & $\begin{array}{l}\text { Autism } \\
\text { SAVANT }\end{array}$ & 35 & 7.97 & 4.462 \\
\cline { 2 - 5 } & Normal & 35 & 0.00 & 0.000 \\
\hline \multirow{3}{*}{ Total Scale } & $\begin{array}{l}\text { Autism } \\
\text { SAVANT }\end{array}$ & 35 & 2.51 & 1.541 \\
\cline { 2 - 5 } & Normal SAVANT & 35 & 2.14 & 1.033 \\
\hline & $\begin{array}{l}\text { Autism } \\
\text { SAVANT }\end{array}$ & 35 & $\mathbf{5 0 . 7 1}$ & $\mathbf{2 4 . 2 8 2}$ \\
\cline { 2 - 5 } & Normal & 35 & 31.49 & 10.311 \\
\hline
\end{tabular}

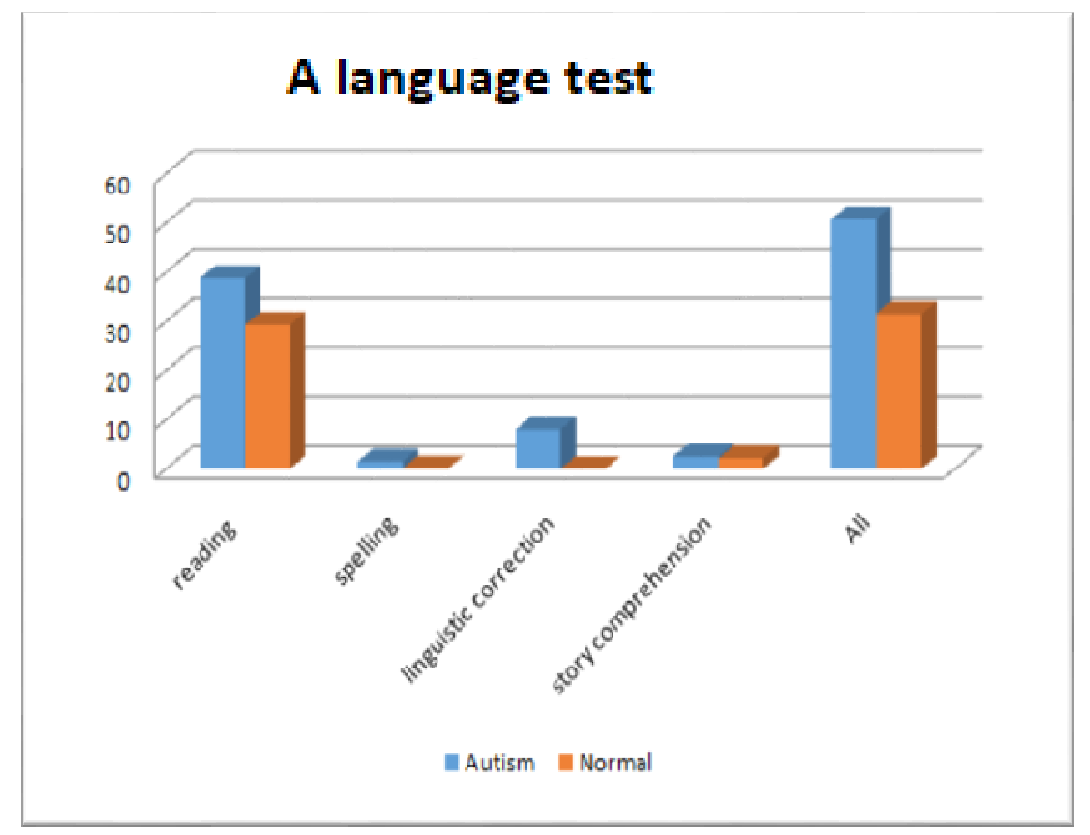

Figure (1) Normal and autistic averages in language testing as a total score and as sub-dimensions. 


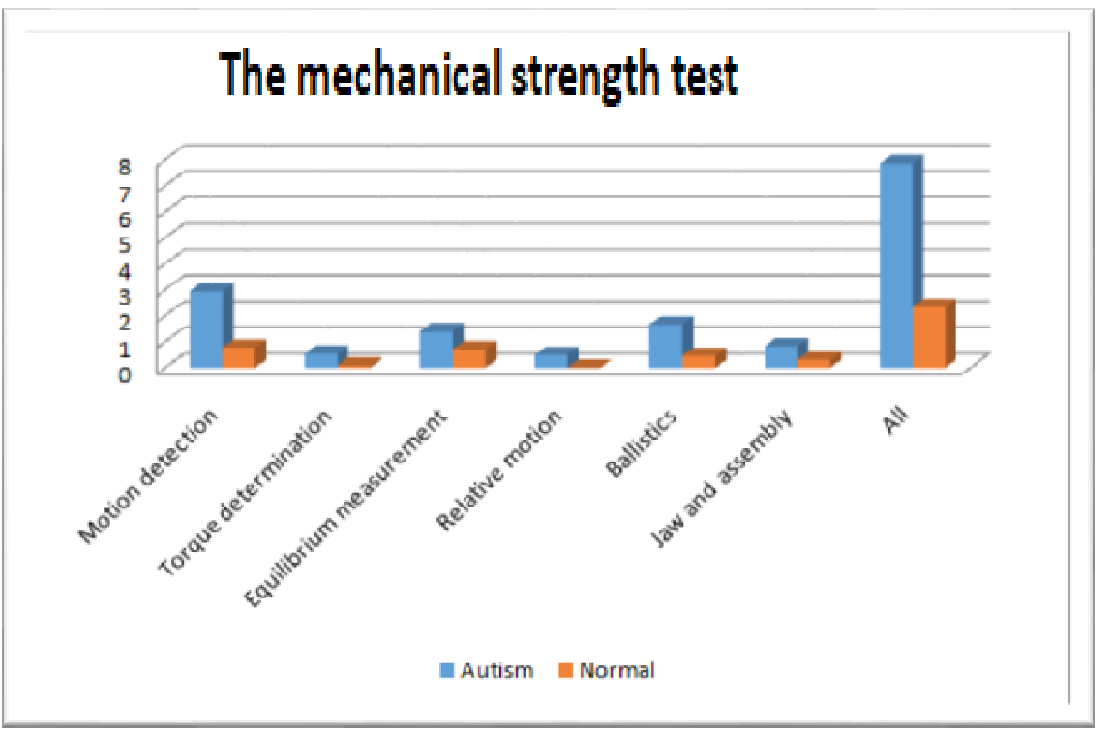

Figure (2) the normal and autistic averages in mechanics as a total score and as sub-dimensions

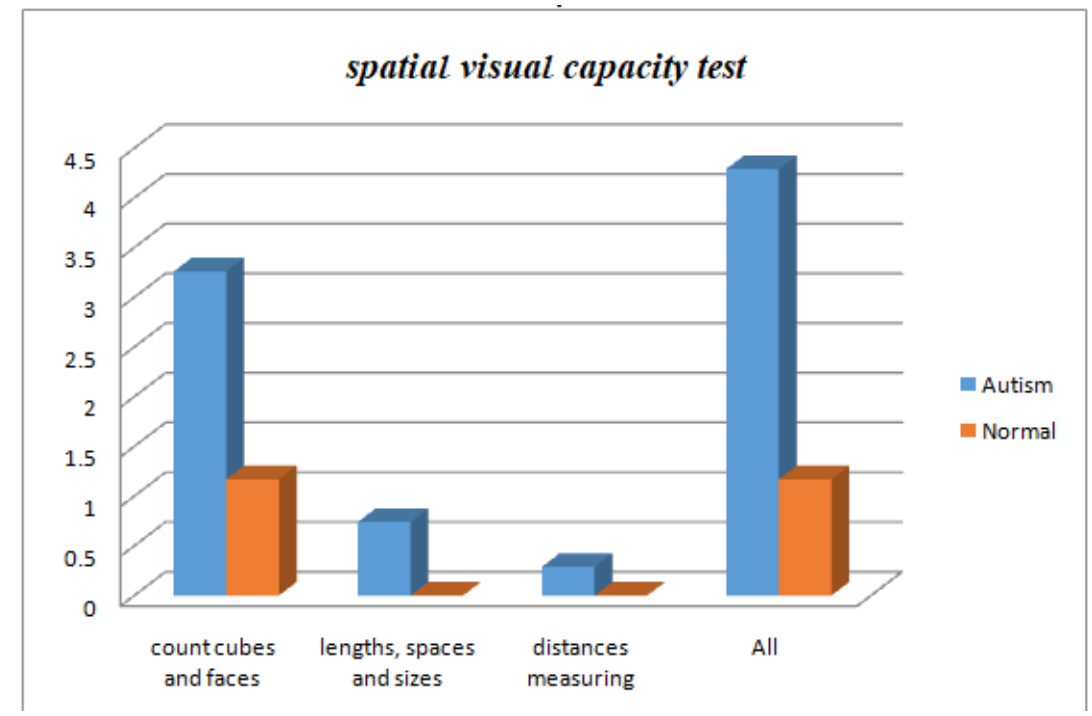

Figure (3) Normal and autistic averages in spatial visual capacity as a total degree and as sub-dimensions. 


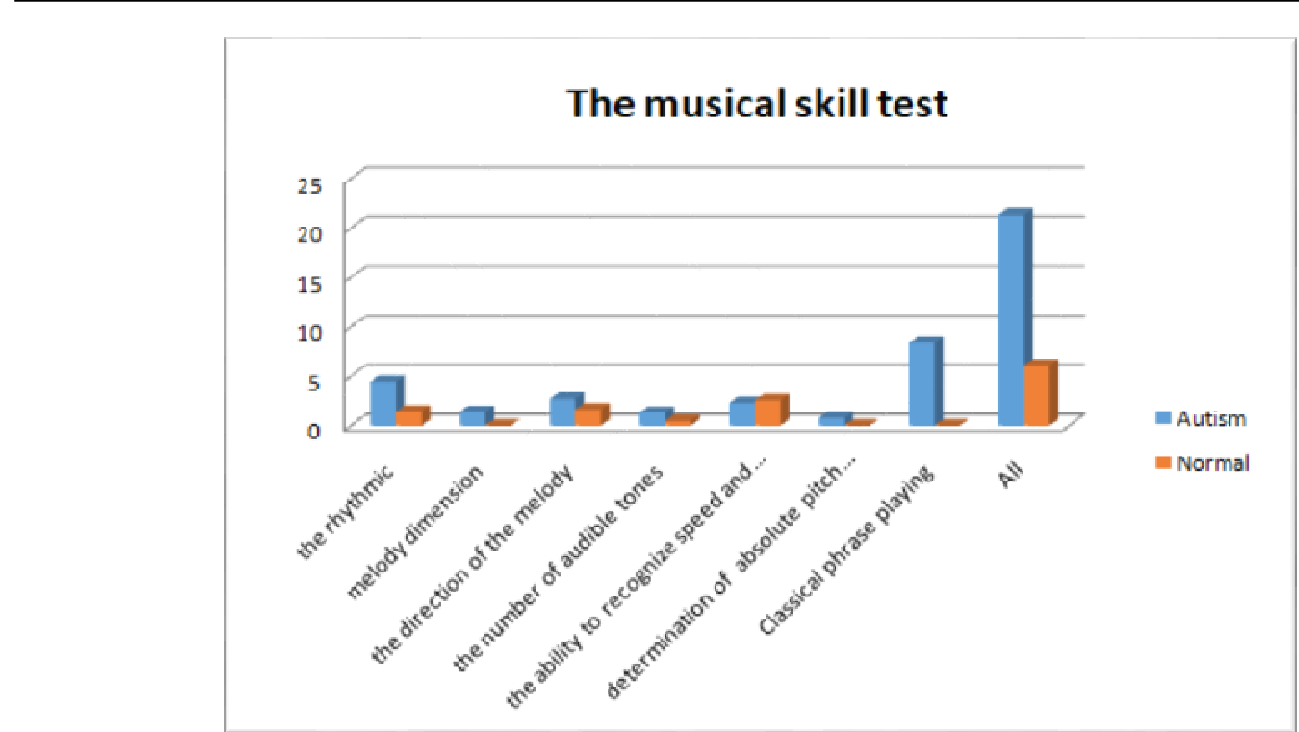

Figure (4) averages of normal and autistic in music as a whole degree and as sub-dimensions.

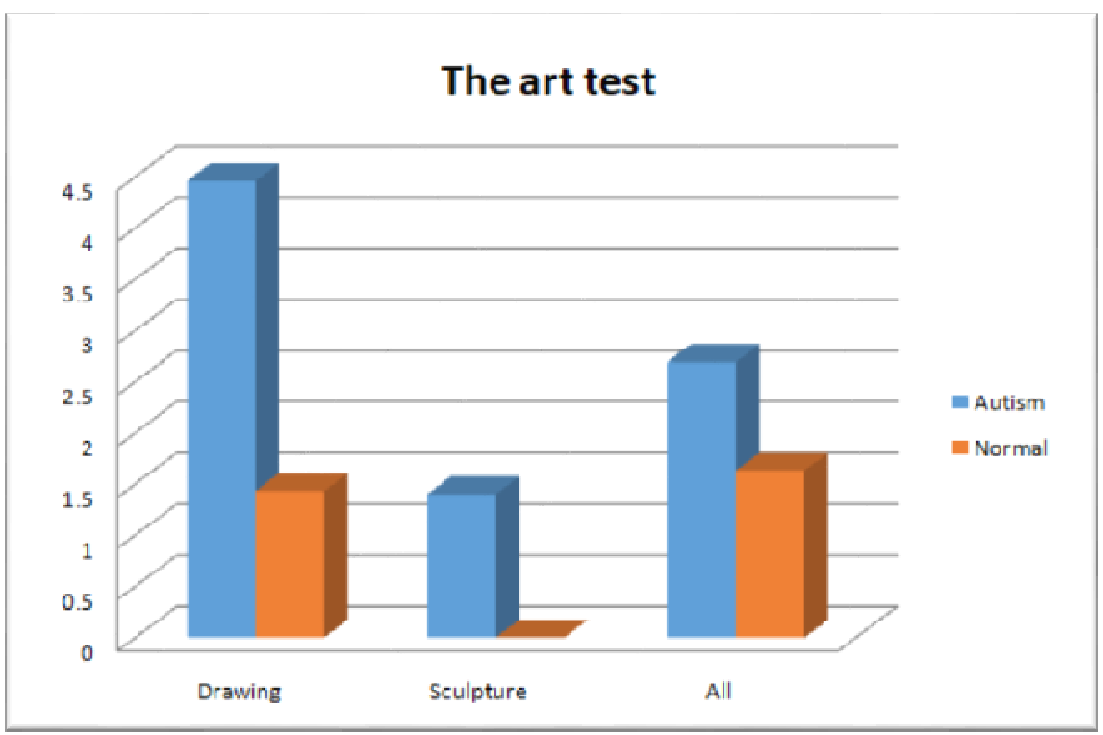

Figure (5) averages of normal and autistic in art as a whole degree and as sub-dimensions. 


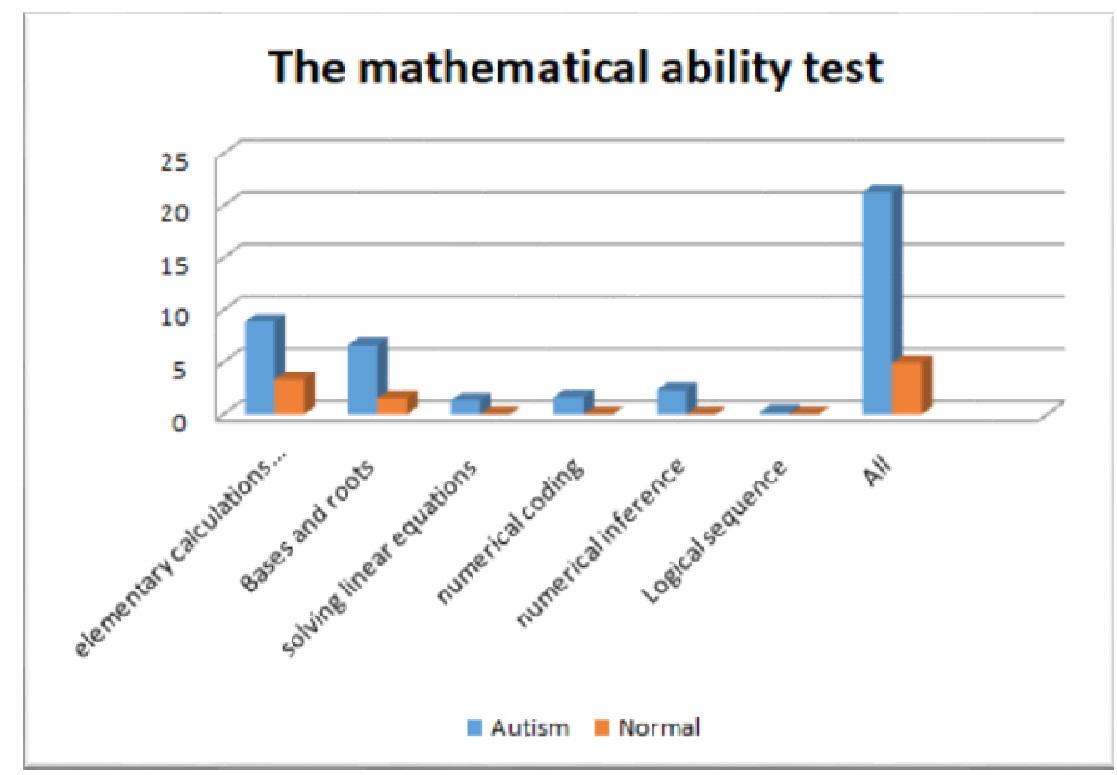

Figure (6) averages of Normal and autistic students in mathematics as a whole degree and as sub-dimensions.

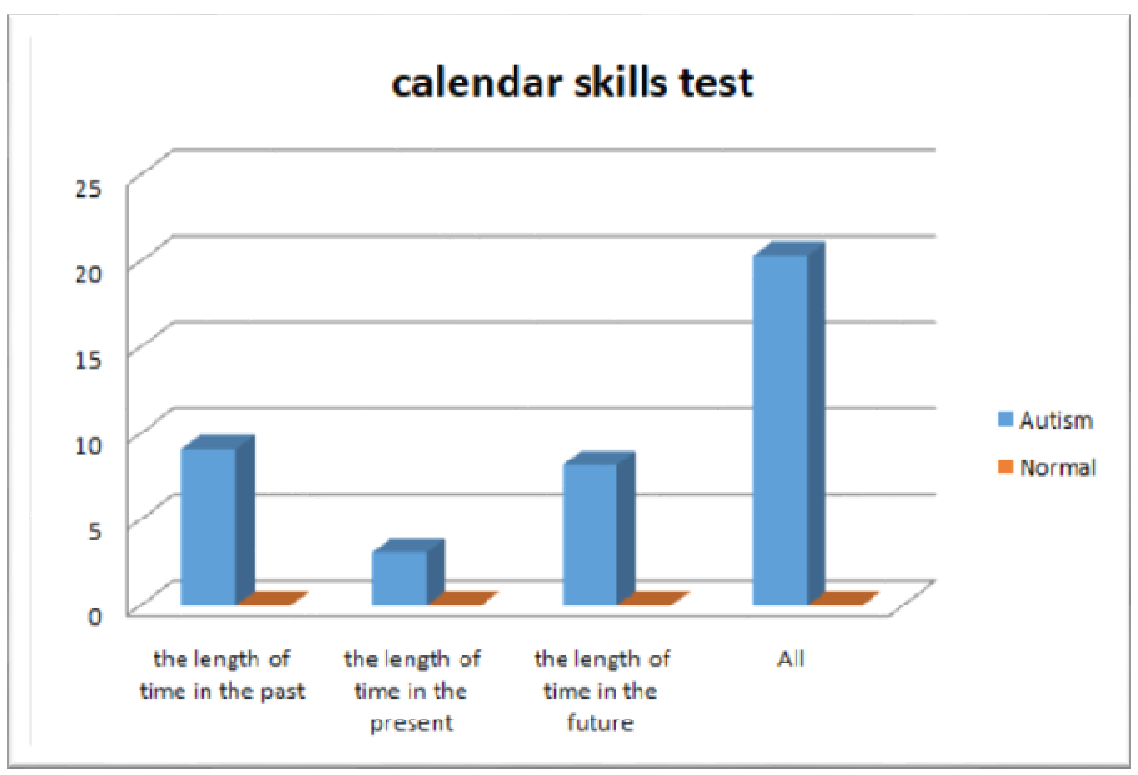

Figure (7) averages of normal and autistic individuals in the calendar as a whole degree and as sub-dimensions.

\section{Tests Battery to determine the abilities of Savant Syndrome of Autism}

The definition of Savant individuals with Autism: It is a rare condition suffering from a neuro-developmental disorders characterized by amazing talent and be innate or acquired in exceptional skills such as music, art, calendar calculation, spatial, mechanical and visual fields and the huge memory, rapid calculation and language. or it may be in one skill or more and the degree of intelligence between 40 to 70 degrees but may be above 70 in $25 \%$ of cases (according to Darold Trafford) and characterized by deficiencies in three areas of social interaction and communications (verbal -non-verbal), stereotypical behaviors and limited activities and interests. We can also determine types of talents or skills of those with savant syndrome through applying the following tests: 


\section{Initial Test: Memory Test}

The first dimension: Memory performance in music.

The Second dimension: Memory performance in the language

The third dimension: Performance visual memory

The Fourth Dimension: Memory performance in mechanics.

The Fifth Dimension: Performance memory in the calendar account

The Sixth dimension: Memory performance in mathematics

The seventh dimension: Memory performance in art

Second: Mechanical capacity Test

The first dimension: motion detection

The Second dimension: torque determination

The Third Dimension: equilibrium measurement The Fourth the Second dimension: measuring Dimension: relative motion

The Fifth Dimension: ballistics

The Sixth dimension: jaw and assembly

Fourth: Mathematical ability Test

The First dimension: Initial calculations

The Second dimension: Foundations and roots

The Third-Dimension numerical coding

The Fourth dimension: Encryption

The Fifth Dimension: numerical inference

The Sixth Dimension: Logical sequence

Sixth: Musical ability Test

The First dimension: rhythmic ability

The Second dimension: melody dimension (measuring the ability to imitate tones)

The Third Dimension: the direction of the melody

The Fourth dimension: the number of audible tones The Fifth

Dimension: the ability to recognize speed and slowness.

The sixth-dimension determination of absolute pitch score.

The seventh dimension: Classical phrase playing.
First: calendar calculation Test

The first dimension: the time period in the past

The Second dimension: the time period in the present

The third dimension: the time period in the future

\section{Third: Spatial capacity Test}

The first dimension: the ability to count cubes and faces

lengths, spaces and sizes.

Third dimension: distances measuring

Fifth: Language Test (Arabic, English,

French, German, Spanish)

The first dimension: the ability to read

The Second dimension: Ability to spell

The Third dimension: linguistic

correction

The fourth dimension: understanding the story

Seventh: Artistic ability Test

First Dimension: Cadence

the Second Dimension: Balance

The third dimension is the artistic work unit

the Fourth dimension: proportion

The sixth dimension: chanting 